\title{
Avaliação Da Educação A Distância Em Um Curso De Administração Contemporâneo
}

\section{Evaluation Of Distance Education In A Contemporary Administration Course}

Mauro Laruccia 1 , Ana Jansen²

1.Mauro Laruccia é pós doutorado em comunicação, doutor comunicação e semiótica pela PUCSP, graduado e especializado em comunicação. Pesquisador e editor de revistas acadêmicas Qualis, é professor de graduação e mestrado. Atua na academia e no mercado de comunicação em São Paulo. mauro.laruccia@gmail.com

2.Ana Maria Jansen Matias é graduada em Administração e mestre em Comunicação e Educação, Professora de Administração nas Faculdades Integradas Campos Salles/SP desde 2010 e na Faculdade Carlos Drummond de Andrade/SP desde 2008. Professora e Coordenadora do curso de Administração na Faculdade São Luís/SP. E-mail: anajansenmatias@hotmail.com

\section{Resumo}

Este trabalho teve como objetivo discutir as contribuições da realização da graduação a distância na formação de estudantes. A pesquisa contemplou dados correspondentes ao tipo de curso considerado, sobre a facilidade de comunicação e interação, facilidade e frequência de utilização de tecnologias, sobre o perfil dos respondentes, e por fim, sobre a contribuição do curso a distancia na sua formação e analisou 126 respostas abertas referentes ao processo de ensino-aprendizagem. A pesquisa revelou que, de forma geral, a EaD contribuiu para formação do aluno. Constatou-se que a EaD é valorizada por boa parte dos alunos por possibilitar o acesso ao ensino superior por motivos diversos: a distância da moradia de instituições de ensino superior; questões relacionadas a dificuldades financeiras e/ou familiares, entre outros. Por fim, boa parte dos participantes elogia esta modalidade de ensino, mas poucos se posicionam quanto ao processo de ensinoaprendizagem e à qualidade do curso oferecido.

Palavras-chave: TIC, EaD, Educação, Formação, Ensino-aprendizagem.

\section{Abstract}

This paper presents discuss contributions to the formation of students in distance education. The survey included data related to the type of course, communication, interaction and frequency of use of technology, profile of respondents, and finally, analyzed 126 responses open regarding the process of teaching and learning. The research revealed that, in general, the DL contributed to development the student. We found that distance education is valued by many of the students by allowing access to higher education 
for several reasons: the distance of the location of institutions of higher education issues related to financial difficulties and / or family, among others. Finally, most of the participants praised this method of teaching, but few are positioned on the teaching learning and the quality of courses offered.

Keywords: ICT, Distance Learning, Education, Formation, Teaching learning.

209 LARUCCIA, M.; JANSEN, A.: Avaliação Da Educação A Distância Em Um Curso De Administração Contemporâneo 


\section{Considerações Iniciais}

A educação a distância tem, cada vez mais, ocupado um lugar extremamente significativo na sociedade do conhecimento, o que provoca transformações em todas as esferas sociais no início do Século XXI. Esta modalidade de educação é um recurso de extrema importância para atender grandes contingentes de alunos.

No Brasil, com a promulgação da nova Lei de Diretrizes e Bases da Educação, em 1996, e o Decreto n..$^{\circ}$ 5622, de 2005, houve um grande aumento no número de cursos oferecidos a distância. Segundo o censo da educação superior, em 2006 existiam 349 cursos superiores de graduação a distância, que contavam com mais de 207 mil alunos matriculados (INEP, 2008).

\section{Educação: Um Reflexo Social}

No contexto da Educação a distância, esta pesquisa tem como objetivo o estudo de dois grupos de estudantes dos Cursos de Administração: alunos de graduação que realizam o curso de forma presencial; e alunos de graduação totalmente a distância. No caso dos alunos da graduação presencial, as disciplinas cujos conteúdos são transmitidos a distância devem ser entendidas como forma complementar da educação, no sentido de gerar processos continuados de acesso ao conhecimento (HORA; GONÇALVES; COSTA, 2008; REIS, 2009).

A educação pode ser considerada como um reflexo da sociedade. Vários fatores, como a situação histórica desta sociedade, o momento cultural, a estrutural social, e a política econômica influenciam diretamente a educação. Assim, podese dizer que a educação é característica de uma determinada sociedade em um determinado momento (ARANHA, 2006; GADOTTI, 2000; HILSDORF, 2003; MANACORDA, 2002). A explosão dos negócios em escala mundial, acompanhada pelo avanço tecnológico da crescente robotização e automação das empresas, faz antever profundas modificações no trabalho e, conseqüentemente, na educação. Nesta perspectiva, a educação a distância passa a ocupar uma posição estratégica e mesmo política, pois o conhecimento está disponível a quem quiser dele se apropriar (LARUCCIA; ALMEIDA; RUIZ, 2010; WERTHEIN, 2000).

$\mathrm{Na}$ tentativa de incorporar as novas tecnologias de informação e comunicação, no entanto, a escola nem sempre tem logrado sucesso porque, muitas vezes, apenas incorpora os novos recursos, sem, no entanto, conseguir alterar a formatação das aulas acadêmicas. Deve-se perceber que o que determina o valor da EAD é a qualidade do projeto pedagógico a ser implementado: seus objetivos, a pertinência e a 
atualidade dos conteúdos, as estratégias didáticas e as relações entre os participantes que devem discutir os problemas levantados pelo grupo. Pode-se considerar, entretanto, que as Tecnologias da Informação e da Comunicação (TICs) entraram de tal forma no mundo contemporâneo, que a escola não tem mais como permanecer artesanal, nem ficar à parte, em plena época da globalização, já que a educação a distância pode ser considerada como uma modalidade de educação em que se utiliza as inovações tecnológicas da sociedade da informação, de forma a responder rapidamente às exigências da sociedade (ATHIYAMAN, 1997; MORAN, 2010).

As novas tecnologias da informação e comunicação não são meros instrumentos no sentido técnico tradicional, mas algo tecnologicamente novo e diferente dentro desse contexto. As tecnologias tradicionais serviam como instrumentos para aumentar o alcance dos sentidos. As novas tecnologias da informação e comunicação ampliam o potencial cognitivo dos seres humanos de forma complexa e cooperativa.

O homem é um ser que fala; é um ser que trabalha e se organiza; pelo trabalho transforma a natureza e a si mesmo ao criar novos instrumentos ou artefatos, isto é, tecnologias. Para completar, devemos enfatizar, ainda, que a ação bumana é uma ação coletiva, na qual o trabalho é executado como uma tarefa social e a palavra toma sentido pelo diálogo, pelas interações. (...) As novas tecnologias digitais estão integrando o mundo em redes. A comunicação mediada por computadores gera uma sociabilidade de redes, online, fundada nos vetores da velocidade, da instantaneidade e da simultaneidade. Nela, trocas sociais e relações pessoais efetuam-se em máxima proximidade, mas na distância, ou seja, com o minimo de contato físico (LARUCCIA, 2004a).

As novas tecnologias da informação e comunicação têm algumas características essenciais: A informação é sua matéria-prima; Os efeitos das novas tecnologias têm alta penetrabilidade; há predomínio da lógica de redes; flexibilidade: crescente convergência de tecnologias (CASTELLS, 2007)

A Declaração Mundial sobre Educação para Todos, da UNESCO, (1990) em seus Princípios de Ação, enfatiza que o primeiro passo deve ser identificar os sistemas tradicionais de aprendizagem existentes na sociedade e a demanda real por serviços de educação básica, seja em termos de escolaridade formal, seja em programas de educação não formal. Deve-se, também, abordar, por todos os meios, as necessidades de aprendizagem básicas, capitalizando o uso de meios tradicionais e modernos de informação e de tecnologias para educar o público.

Dentre as relações sociais, as tecnologias da informação e comunicação são cada vez mais 
usadas nas organizações de trabalho, a fim de coletar, armazenar e processar um grande número de informações, para controle dos equipamentos e processos de trabalho, para conectar as pessoas e escritórios, tanto dentro quanto entre as organizações. A utilização destas tecnologias da informação e comunicação na vida diária significa a possibilidade de modernização das diferentes culturas, já que a utilização dos instrumentos da tecnologia da informação e comunicação significa novas formas de interação entre homem-máquina. No mercado de trabalho, inclusive, o indivíduo deve ser capaz de absorver e utilizar a informação a serviço da empresa, já que não é possível ignorar a verdadeira revolução que as tecnologias da informação e comunicação desempenham. Estas tecnologias conferem grandes vantagens ao esforço do homem para sobreviver e competir no ambiente organizacional. As tecnologias da informação e comunicação são um dos principais agentes transformadores das organizações, pois seus diversos usos e implicações contribuem para as alterações na forma de conhecer o mundo e na forma de representar esse conhecimento (LARUCCIA; MELO, 2009; LARUCCIA, 2004b).

A capacitação e formação do cidadão somente se darão através da educação. A educação entendida como criação de competências suficientemente amplas que permitam uma atuação efetiva da produção de bens e serviços, tomar decisões fundamentadas no conhecimento, operar os novos meios e ferramentas em seu trabalho, bem como aplicar novas mídias criativamente, em ações rotineiras ou mais complexas. Neste contexto, a Educação a Distância insere-se como alternativa para rápida difusão do material didático e de informação entre pais, professores e alunos, permitindo a construção interdisciplinar de informações produzidas individualmente, bem como $\mathrm{O}$ desenvolvimento de projetos por parte de indivíduos geograficamente dispersos. O papel das tecnologias de informação e comunicação é gerar a produção de bens e serviços e transferir estas aquisições para o setor produtivo, onde deve ocorrer sua aplicação em novos bens e serviços, disseminando sua aplicação. $\mathrm{O}$ ensino a distância deve tornar-se uma realidade em larga escala e, dentre outras iniciativas, transformar-se no instrumento para a capacitação tecnológica e a inclusão digital.

\section{Educação A Distância}

A Educação a Distância só é possível porque existem tecnologias da informação e comunicação que possibilitam estabelecer um processo de comunicação mesmo quando alunos e professores encontram-se fisicamente distantes - é, portanto, possível graças às TICs. Sem limitação de lugar, tempo, profissão ou idade dos alunos. Entretanto, se antes, educação a distância 
podia ser caracterizada como o sistema educacional onde há total separação física entre professor e aluno (em contraposição com a educação presencial), hoje, a fronteira entre educação a distância e educação presencial encontra-se cada vez menos nítida, pois a interação pessoal em sala de aula está sendo substituída pela ação sistemática de diversos recursos didáticos e pelo apoio de uma organização de tutoria, que propicia aprendizagem independente dos alunos (WERTHEIN, 2000). O uso da educação a distância no Brasil registra boas experiências, porém, foram utilizadas pontualmente e, na maioria dos casos, não tiveram tempo de serem avaliadas e adotadas como políticas de Estado (LARUCCIA, 2008). Associadas à proposta de mudança, surgem resistências movidas pela insegurança e medo do desconhecido. As atitudes dos estudantes com relação à educação a distância são indicadores tão importantes quanto seu desempenho na identificação da eficácia dos cursos e dos programas realizados a distância (VALENTA, THERRIAULT, DIETER \& MRTEK, 2001).

O Ministério da Educação foi além, ao permitir, por meio da Portaria MEC 4059, de 10 de dezembro de 2004, que as IES (Instituições de Ensino Superior) ministrem até $20 \%$ de seus cursos reconhecidos a distância. Tal prática caracteriza um ensino semipresencial, visto que os $80 \%$ restantes são presenciais. Ao incluir, em seu currículo, parte das disciplinas no formato não presencial, as instituições de ensino superior passaram a contribuir para a disseminação da cultura da educação a distância. A maior divulgação deste formato de educação criou um mercado de fronteiras cada vez mais elásticas (LARUCCIA, 2008). As transformações associadas à nova realidade de ensino não são pequenas, visto que envolvem muito mais do que a simples alteração de ambiente educacional, abrangem todo um aparato didático e social, devido à necessidade de alterações metodológicas e também das relações vigentes, sejam essas humanas, tecnológicas ou de conhecimento. É importante salientar que a educação a distância não pode ser compreendida como substituta da educação convencional, presencial. São duas modalidades do mesmo processo, já que pedagogia e tecnologia (entendidas como processos sociais) sempre andaram em paralelo: o processo de socialização das novas gerações inclui necessária e logicamente a preparação dos jovens para o uso dos meios técnicos disponíveis na sociedade, seja a caneta seja o computador. Um dos desafios para a EaD, é a superação dos preconceitos, que chegam a considerá-la apenas como um processo de contenção de despesas, ou uma educação de segunda categoria, uma maneira disfarçada de esvaziar o ensino regular e prescindir de recursos humanos exigidos pela educação presencial (TORI, 2010). 
A EaD, porém, não significa uma simplificação do processo ensino-aprendizagem, uma vez que todo referencial teórico necessário à aquisição das competências e habilidades que promovam o desenvolvimento do indivíduo, o exercício da cidadania e a autonomia para continuar aprendendo é exatamente o mesmo para ambas as formas de ensino: presencial e a distância. Os responsáveis pelas políticas institucionais e governamentais têm introduzido a $\mathrm{EaD}$ para atender certas necessidades, como: (a) acesso crescente a oportunidades de aprendizado e treinamento; (b) proporcionar oportunidades para atualizar aptidões; (c) melhorar a redução dos custos dos recursos educacionais; (d) apoiar a qualidade das estruturas educacionais existentes; (e) melhorar a capacitação do sistema educacional; (f) nivelar desigualdades entre grupos etários; (g) direcionar campanhas educacionais para públicosalvo específicos; (h) proporcionar treinamento de emergência para públicos-alvo importantes; (i) aumentar as aptidões para a educação em novas áreas do conhecimento; (j) oferecer uma combinação de educação com trabalho e vida familiar; (k) agregar uma dimensão internacional à experiência educacional (MOORE et al., 2007).

Como forma integradora de parcelas da sociedade, a Educação a Distância pode ser empregada para a formação e atualização de contingentes populacionais com pouca escolaridade, mas com grande experiência de vida, se adaptando às múltiplas realidades dessas pessoas e buscando, inclusive, sua transformação em cidadãos ativos na sociedade. A educação, assim, deve trabalhar mais com o significado do que com o conteúdo, sendo a tecnologia o meio, o instrumento para o desenvolvimento da aprendizagem.

O aluno, situado neste contexto de mudanças, deve: aprender a conhecer, aprender a fazer, aprender a ser e aprender a conviver (DELORS, 1996). A educação, além de transmitir informações, tem que formar um cidadão que saiba transformar estas informações em conhecimento, em ação e desenvolver habilidades e competências capazes de lidar com esta gama de informações, para realizar seu projeto de vida. Nesse contexto, os alunos podem ser levados a compreender a Educação a Distância como mero meio de armazenamento e disseminação de conteúdos, e não como modelo de ensino/aprendizagem que utiliza tecnologias da informação e comunicação para mediar parte desse processo. $\mathrm{Na}$ percepção dos alunos, o não cumprimento das obrigações da instituição de prover uma situação de ensino/aprendizagem coerente com o esquema representativo tradicional, afeta negativamente a percepção global do aluno de que a instituição pode não estar comprometida com ele. É nesse contexto que a avaliação é um elemento fundamental do processo de ensino e aprendizagem, pois é por meio dela que se concretizam os objetivos do ensino. Além disso, ela contém e está contida no conteúdo e no 
método efetivado na prática pedagógica com uma abordagem em que não há ensino sem aprendizagem e que a ação docente se efetiva na relação com o aluno (MASETTO, 2010; ROMANOWSKI, 2008; SEGENREICH, 2006; VIEIRA; FREITAS, 2010).

\section{Materiais E Métodos}

Como Metodologia desta pesquisa, serão divididas em três as categorias de tipologia de pesquisa: quanto aos objetivos, quanto aos procedimentos e quanto à abordagem do problema. A partir da questão problema elaborada, pode-se definir que a tipologia quanto aos objetivos consiste em uma pesquisa descritiva. Já quanto aos procedimentos, em que se decide de qual forma se irão coletar os dados, será utilizado o levantamento de dados ou survey. Em relação à abordagem do problema trata-se de uma pesquisa qualitativa-quantitativa (CARSON, 2001; CURWIN; SLATER， 2008; LIMA， 2004; LÜDKE; ANDRÉ, 2008; SOUZA， 2006; VERGARA, 2011). É um estudo do tipo qualitativo, pois trabalha com valores, crenças, hábitos, atitudes, representações, opiniões e adequa-se a aprofundar a complexidade de fatos e processos particulares e específicos a indivíduos e grupos em questão aberta.
O universo da pesquisa foi constituído por 300 alunos de graduação, presencial e semipresencial, do curso de Administração de uma IES da Grande São Paulo. Conforme McDaniel \& Gates (2003, p.372), adotou-se o tipo de amostragem não-probabilística aleatória, que inclui elementos de uma população selecionados de maneira não aleatória, na base da conveniência, neste caso, a dos alunos de uma IES, porque são fáceis e baratos de encontrar, porém, com a vantagem de poder ter certeza de obter informações de um corte transversal representativo da população de interesse. Segundo Lima (2004, p.83), “as amostragens nãoprobabilísticas são frequentemente utilizadas em razão da inacessibilidade ao universo total que é composto a população-alvo da pesquisa”.

Os dados primários foram obtidos por meio de questionário do tipo semi-estruturado, desenvolvido pelos pesquisadores. Com uso de questionários na Internet, os entrevistados completam a pesquisa e os dados são automaticamente coletados e tabulados (MCDANIEL; GATS, 2003). De acordo com Moreira (2002), as perguntas possuem uma ordem, no entanto, por ser respondida on-line foi permitido aos pesquisados liberdade de avançar e retroceder para opinarem mais livremente.

No questionário formularam-se perguntas fechadas, semi-abertas, abertas, de múltipla escolha, de avaliação, questões de fato, questões 
de opinião e de intenção, conforme descreve Lima (2004, p.50-71). O questionário foi apresentado com 11 (onze) perguntas. Contemplou dados correspondentes ao tipo de curso considerado, sobre a aquisição de competências, habilidades e atitudes, sobre o perfil dos respondentes, e por fim, sobre dificuldades de ensino-aprendizagem. Não houve participação nenhuma dos pesquisadores, ou seja, o questionário ficou à disposição dos respondentes no ar, on-line, e foi preenchido e coletado pelo sistema do Qualtrics Survey Software.

Para a coleta de dados por meio do questionário, inicialmente foram enviadas 300 mensagens por e-mail $(100 \%$ dos alunos potenciais), buscando-se receber um retorno de 10\% desses alunos potenciais (30 membros do universo). Este primeiro grupo de alunos foi selecionado aleatoriamente a partir da verificação no cadastro da IES pesquisada. $O$ total de respondentes foi de 104, ou seja, a pesquisa de campo apresentou uma amostra de 34,6\% (trinta e quatro vírgula seis por cento) da população total, e que obteve acesso para sua efetivação. Desses 104 respondentes, 99 responderam todas as questões.

\section{Resultados}

Apresenta-se a seguir as tabelas com as respostas dos alunos envolvidos na pesquisa: $\mathrm{O}$ perfil dos respondentes, conforme tabela 1, apresentou as seguintes características: $56 \%$ são mulheres de 19 a 29 anos (58\%), da região sudeste (88\%), de alunos de graduação presencial que utiliza o EaD para cumprir carga horária (59\%), que tinha familiaridade com as tecnologias do $\mathrm{EaD}(61 \%)$, que não encontrou dificuldade com a utilização da tecnologia durante o curso (58\%), e que faria outro curso a distância (56\%).

\section{Quadro 01: Perfil dos Respondentes}

Perfil dos Respondentes

$159 \%$ de alunos de graduação semipresencial

$256 \%$ mulheres

$358 \%$ entre 19 e 29 anos

$488 \%$ da Região Sudeste

$544 \%$ utilizou o AulaNet como LMS (Learning Management System)

$6 \quad 61 \%$ tinha familiaridade com as tecnologias digitais

$7 \quad 58 \%$ não encontrou dificuldade com a utilização da tecnologia durante o curso

$8 \quad 81 \%$ superior incompleto

$956 \%$ faria outro curso a distância

Os alunos foram questionados quanto à contribuição da modalidade de ensino a distância em sua formação acadêmica, tendo participado da pesquisa 99 estudantes, com um total de 126 respostas, pois alguns alunos apontaram mais de um aspecto referente ao seu processo de ensinoaprendizagem. Deste total, 101 afirmativas foram favoráveis e 25 criticam a modalidade de ensino a distância (quadro 02). 
QUADRO 02 - total de respostas quanto à contribuição da modalidade de ensino a distância na formação acadêmica

\begin{tabular}{|l|l|l|}
\hline Posicionamentos & $\begin{array}{l}\text { Número } \\
\text { de } \\
\text { respostas }\end{array}$ & $\%$ \\
\hline $\begin{array}{l}\text { Favoráveis à aprendizagem por meio } \\
\text { da EaD }\end{array}$ & 101 & 80 \\
\hline $\begin{array}{l}\text { Desfavoráveis à aprendizagem por } \\
\text { meio da EaD }\end{array}$ & 25 & 20 \\
\hline Total & 126 & 100 \\
\hline
\end{tabular}

Das 101 respostas favoráveis ao $\mathrm{EaD}$ na formação acadêmica, constatou-se que as respostas se apresentaram em cinco dimensões: referentes à própria modalidade de $\operatorname{EaD}(36,6 \%)$; referentes ao processo de ensino aprendizagem $(32,6 \%)$; referentes ao desenvolvimento de competências, habilidades e posturas (12,8\%); referentes ao trabalho e/ou vida profissional $(11,8 \%)$ e referentes a aspectos pessoais dos alunos $(5,9 \%)$, conforme quadro 03 .

QUADRO 03 - respostas favoráveis ao ensino a distância

\begin{tabular}{|l|l|l|}
\hline Dimensões & $\begin{array}{l}\text { Número } \\
\text { de } \\
\text { respostas }\end{array}$ & $\%$ \\
\hline $\begin{array}{l}\text { Referentes à própria modalidade } \\
\text { de EaD }\end{array}$ & 37 & 36,6 \\
\hline $\begin{array}{l}\text { Referentes ao processo de } \\
\text { ensino-aprendizagem }\end{array}$ & 33 & 32.6 \\
\hline $\begin{array}{l}\text { Referentes ao desenvolvimento } \\
\text { de habilidades, competências e } \\
\text { posturas }\end{array}$ & 13 & 12,8 \\
\hline $\begin{array}{l}\text { Referentes ao trabalho e/ou vida } \\
\text { profissional }\end{array}$ & 12 & 11,8 \\
\hline $\begin{array}{l}\text { Referentes a aspectos pessoais } \\
\text { dos alunos }\end{array}$ & 06 & 5,9 \\
\hline Total & 101 & 99,7 \\
\hline
\end{tabular}

Na dimensão referente à especificidade de Educação a Distância como fator favorável, encontram-se respostas das quais se destacam os seguintes aspectos: flexibilidade de horário (56,7\%); acesso ao ensino superior (21,7\%); praticidade (10,8\%); comodidade (5,4\%) e um participante respondeu que não vê diferença entre o ensino presencial e a modalidade a distância (quadro 04).

QUADRO 04 - respostas referentes à contribuição da EaD relacionadas à própria modalidade de ensino

\begin{tabular}{|l|l|l|}
\hline Dimensões & $\begin{array}{l}\text { Número de } \\
\text { respostas }\end{array}$ & $\%$ \\
\hline Flexibilidade de horário & 21 & 56,7 \\
\hline $\begin{array}{l}\text { Acesso ao ensino } \\
\text { superior }\end{array}$ & 08 & 21,7 \\
\hline Praticidade & 04 & 10,8 \\
\hline Comodidade ao & 02 & 5,4 \\
\hline $\begin{array}{l}\text { Acesso facilitado anteúdo } \\
\text { conterenç entre o }\end{array}$ & 01 & 2,7 \\
\hline $\begin{array}{l}\text { Não vê diferena } \\
\text { presencial e a EaD }\end{array}$ & 37 & 2,7 \\
\hline Total & 100 \\
\hline
\end{tabular}

As questões que mais se evidenciam quanto à modalidade a distância e a contribuição que proporcionam aos estudantes é a flexibilidade de horário, com 16 afirmativas, e o acesso ao ensino superior, com 8 respostas, como se pode verificar em seus depoimentos:

1- É exatamente a possibilidade de fazer uma graduação, coisa que sem o EaD seria quase impossível conciliar meus horários (P 05);

2 - O tempo é curto, pois trabalho o dia inteiro e tenho uma filha pequena (P 24); 
3 - Acesso à informação e uma alternativa para minha vida corrida. De outra maneira não teria tempo para estudar. (P 27);

4 - Ajuda pela falta de tempo para realizar cursos presenciais (P 29);

5 - [...] moro afastada de grandes centros, e na minha vida atual não disponho de tempo para aulas presenciais, sendo essa portanto a única maneira de completar minha graduação (P 57);

6 - Dinamismo e liberdade de horário de estudo (P 83);

7 - [...] um curso a distância proporciona mais tempo para estudar, (P 85);

8 - [...] e com o curso a distância posso me dedicar mais aos estudos (P 85).

Vale lembrar que um dos principais objetivos do Ministério da Educação em apoiar e incentivar o desenvolvimento da Educação a Distância no país é, entre outros aspectos, proporcionar à população a oportunidade de estudar e que, por motivos diversos, não tem acesso ao ensino superior.

Vários fatores dificultam estes educandos a cursar o ensino superior na modalidade presencial, como por questões do tempo para o estudo, o trabalho por turnos, em que o trabalhador não tem um horário fixo de trabalho, o excesso de atividades e a dificuldade em conciliar o trabalho com atividades domésticas, como educar filhos e administrar as tarefas de organização da moradia, a distância entre a residência/trabalho e as instituições de ensino superior etc.

Já quanto ao processo de ensinoaprendizagem propiciado pelo $\mathrm{EaD}, 34$ afirmativas na pesquisa, elogiam essa modalidade de ensino em várias dimensões: adquirir conhecimento (30,4\%); favorecer a aprendizagem $(21,3 \%)$; conhecer novas tecnologias (12,1\%); desenvolver a leitura e/ou a escrita (12,1\%); conhecer novos métodos (6\%); incentivar a pesquisa (12,1\%); conhecer outras modalidades (6\%); como se pode constatar no quadro 05 .

QUADRO 05 - respostas referentes à contribuição da EaD relacionadas ao processo de ensinoaprendizagem

\begin{tabular}{|l|l|l|}
\hline Dimensões & $\begin{array}{l}\text { Número } \\
\text { de } \\
\text { respostas }\end{array}$ & $\%$ \\
\hline Adquirir conhecimento & 10 & 30,4 \\
\hline Favorece a aprendizagem & 07 & 21,3 \\
\hline $\begin{array}{l}\text { Conhecimento de novas } \\
\text { tecnologias }\end{array}$ & 04 & 12,1 \\
\hline Incentivo à pesquisa da leitura & 04 & 12,1 \\
\hline $\begin{array}{l}\text { Desenvolvimento de novos } \\
\text { e/ou escrita }\end{array}$ & 02 & 12,1 \\
\hline $\begin{array}{l}\text { Conhecimento de } \\
\text { métodos de ensino de outras }\end{array}$ & 02 & 6,0 \\
\hline $\begin{array}{l}\text { Conhecimento de } \\
\text { realidades }\end{array}$ & 33 & 100 \\
\hline Total & & \\
\hline
\end{tabular}

Das 33 respostas que identificam que a EaD colabora no seu processo de ensinoaprendizagem, 10 pontuam que auxilia na aquisição do conhecimento e 07 destacam que a 
modalidade a distância favorece sua aprendizagem, o que se constata em suas afirmativas:

- A mesma que um curso presencial, ou seja, a possibilidade de crescimento pessoal e profissional com a construção do conhecimento (P 50).

- O aprendizado é a melhor contribuição (P 14).

- O aprendizado é mais dinâmico, simples e objetivo (P 96).

- Um aprendizado a mais. Aprendi muito e acho que vai me ajudar muito na minha carreira (P 38)

Os depoimentos revelam que o $\mathrm{EaD}$ consegue bom resultado no processo de ensinoaprendizagem de alguns estudantes, que valorizam e elogiam a experiência que tiveram. Esse aspecto é importante, uma vez que ainda hoje se percebe uma desconfiança de algumas pessoas no potencial educativo da $\mathrm{EaD}$, que por se estruturar de forma diferenciada e necessitar de maior disciplina do educando, entre outros fatores, gera inseguranças no meio social frente à capacidade de gerar um processo educativo significativo na formação acadêmica dos alunos. Notou-se que para alguns estudantes não houve prejuízo em seu processo formativo, pois reconhecem que a modalidade a distância favoreceu $\mathrm{O}$ seu aprendizado e afirmam que ampliaram seu conhecimento após a realização do curso. O conhecimento de novas tecnologias, também foi apontado como um aspecto positivo na EaD, sendo referendado nas citações abaixo:
- Acabamos nos familiarizando mais com uma ferramenta que hoje em dia é essencial (P 17).

- Possibilidade de conhecimento de tecnologias (P 11)

- Adequação a novas tecnologias que são importantes no mercado de trabalho $(\mathrm{P}$ 16).

Este é um aspecto relevante, se considerar que a utilização das novas tecnologias é uma realidade no contexto do mercado de trabalho da atualidade, sendo de fundamental importância as experiências e vivências dos educandos no âmbito educacional com essas mídias, que podem ser significativas na formação dos futuros profissionais, ultrapassando a utilização corriqueira, descontextualizada e descompromissada das novas mídias que geralmente são observadas no cotidiano. Assim:

\footnotetext{
Ao possibilitar que o homem se desenvolva tendo em vista os novos modos de ser na sociedade contemporânea, a nova lógica que orienta as atividades de ensino na instituição coloca-o olhando para si mesmo e para seus anseios pessoais e coletivos. Identifica-o em sua absoluta humanidade desenvolvida paradoxalmente por meio de suas inter-relações com as mais novas tecnologias de comunicação e de informação (KENSKI, 2006, p. 97).
}

Desta maneira, quando o contexto educacional propicia ao aluno uma aproximação com as tecnologias digitais com o enfoque pedagógico e como ferramenta que o auxilie a dar 
um novo sentido à relação com as tecnologias, pode favorecer o educando no desenvolvimento de habilidades e competências perante as novas mídias para atuar no meio social e na sua inserção no mercado de trabalho. $\mathrm{Na}$ dimensão relativa à EaD como forma de auxiliar no desenvolvimento da leitura e/ou da escrita, constataram-se quatro relatos, entre eles:

- Estímulo da leitura e interpretação de textos e na facilidade de expressão (P 19). - Me ajudou muito em relação à língua portuguesa [...] e está me ajudando muito para estudar - - para o concurso, resumindo este curso a distancia é 1000 , melhor impossível (P 70).

Este desenvolvimento da escrita e da leitura está, em parte, associado às próprias características da modalidade de ensino a distância, por exigir que o aluno faça as leituras indicadas pelo professor e realize as atividades e/ou reflexões por meio da elaboração de textos. Os momentos para a realização dessas tarefas acabam proporcionando ao educando o estabelecimento de uma rotina em seu aprendizado, que provavelmente não tenha sido tão intensa em sua formação no ensino fundamental e médio.

Este resultado está alinhado com o pensamento de Delors (1996), que em relatório apresentado à Comissão Internacional sobre a Educação para o Século XXI, produzido para a UNESCO, defende que a educação deve se organizar em quatro eixos, sendo um deles o de “Aprender a aprender", que explicita, entre outros aspectos, que o domínio da leitura e da escrita são fundamentais na formação das novas gerações. Tal desenvolvimento proporciona ao educando a construção das bases que lhe permitirão continuar aprendendo ao longo da vida e para que tenha compreensão do real, de forma crítica e sensível ante as prerrogativas mundiais.

Outro fator, também, apontado pelos alunos foi o incentivo à pesquisa, citado em quatro momentos, dado importante, visto que demonstra que a $\mathrm{EaD}$, por sua própria estrutura e dinâmica, desafia o aluno a buscar o conhecimento em outras fontes, o que nem sempre se pode constatar na modalidade presencial, pois a facilidade de acesso ao docente pode até desencadear um processo de dependência e acomodação do aluno, que, muitas vezes, supre suas dúvidas no relacionamento direto com o professor.

Nas respostas referentes à $\mathrm{EaD}$ e ao processo de ensino-aprendizagem, também foram lembrados o conhecimento de novos métodos de ensino e de novas realidades, com duas citações cada. No aspecto relacionado à EaD como favorecendo o desenvolvimento de habilidades, competências e posturas, encontram-se doze referências, sendo a autonomia citada por $66,6 \%$ desse total e a responsabilidade e a disciplina por $16,7 \%$ cada (quadro 06). 
QUADRO 06 - respostas referentes à contribuição da EaD relacionadas ao desenvolvimento de habilidades, competências e posturas

\begin{tabular}{|l|l|l|}
\hline Dimensões & $\begin{array}{l}\text { Número de } \\
\text { respostas }\end{array}$ & $\mathbf{\%}$ \\
\hline Autonomia & 08 & 66,6 \\
\hline Responsabilidade & 02 & 16,7 \\
\hline Disciplina & 02 & 16,7 \\
\hline Total & 12 & 100 \\
\hline
\end{tabular}

$\mathrm{O}$ aspecto mais citado nesta dimensão foi que a modalidade de ensino a distância favoreceu o desenvolvimento da autonomia, conforme citações:

- Aprender de forma autônoma e com qualidade, independentemente do local que o mesmo está sendo realizado (P 06). - Ter comprometimento, responsabilidade com a entrega de trabalhos e de adquirir conhecimento $(\mathrm{P}$ 09).

- Aprender a buscar e como buscar o conhecimento, ao invés de esperar ele cair da mesa do professor no nosso colo (P 99).

Os três aspectos, a autonomia, a responsabilidade e a disciplina são posturas, habilidades e competências que o processo educativo a distância possibilita em seu desenvolvimento, uma vez que depende do aluno organizar, acompanhar e estabelecer estratégias de estudo e de pesquisa em rotinas que envolvam o seu trabalho ou estudo. Claro que tais comportamentos também podem ser incentivados e incorporados em cursos presenciais, porém, na $\mathrm{EaD}$, são aspectos indispensáveis e fundamentais para que o aluno construa um processo de aprendizagem significativo, o que ocorre por conta de, em muitos momentos, ter que ser o sujeito de seu processo de aprendizagem, visto que "Não há educação e aprendizagem sem sujeito da educação e da aprendizagem. A participação pertence à própria natureza do ato pedagógico" (ANTUNES, 2002, p. 138).

A última dimensão que se refere à EaD como favorável ao processo de ensinoaprendizagem dos estudantes participantes desta pesquisa contempla as questões do universo do trabalho com sete afirmativas que relacionam a aprendizagem a distância à evolução profissional e quatro relacionadas à aprendizagem como uma forma de acessar o mercado de trabalho (quadro 07).

QUADRO 07 - respostas referentes à contribuição da EAD relacionadas ao trabalho

\begin{tabular}{|l|l|l|}
\hline Dimensões & $\begin{array}{l}\text { Número de } \\
\text { respostas }\end{array}$ & $\%$ \\
\hline Evolução profissional & 07 & 63,63 \\
\hline $\begin{array}{l}\text { Acesso ao mercado de } \\
\text { trabalho }\end{array}$ & 04 & 36,36 \\
\hline Total & 11 & 99,9 \\
\hline
\end{tabular}

As questões profissionais foram lembradas pelos participantes, que destacam que a $\mathrm{EaD}$ contribuiu em sua formação como forma de evoluir na carreira, como por exemplo: 
Graças a este curso estou empregada (P 03).

Auxiliou meu desenvolvimento profissional (P 28).

Além do aprendizado que me proporcionou, o diploma que é exigido pelo mercado, e com o reconhecimento do MEC (P 93).

Já, das 25 citações que afirmam que a EaD não favoreceu seu processo de ensinoaprendizagem, 11 referências destacam que não houve por esse método nenhuma colaboração em sua aprendizagem, 4 postulam que não gostaram da modalidade a distância e 6 que se reportam ao afastamento dos professores como um dificultador em seu processo educativo (quadro 08).

QUADRO 08 - respostas desfavoráveis quanto à contribuição da EaD no processo de ensinoaprendizagem

\begin{tabular}{|l|l|l|}
\hline Dimensões & $\begin{array}{l}\text { Número de } \\
\text { respostas }\end{array}$ & \% \\
\hline Nenhuma & 15 & 60 \\
\hline Afastamento do professor & 06 & 24 \\
\hline Não gosta da modalidade & 04 & 16 \\
\hline Total & 25 & 100 \\
\hline
\end{tabular}

Dos 15 participantes da pesquisa que afirmam que a $\mathrm{EaD}$ não colaborou em seu processo de aprendizagem, merecem destaque os seis alunos que fazem críticas à $\mathrm{EaD}$ e relacionam sua insatisfação à postura do professor e/ou de seu afastamento do aluno, conforme as citações:
- Seria melhor com mais explicações por parte dos professores (P 23).

- Nenhuma, pois o curso à distância está dificultando o aprendizado do aluno, e não sabemos nem por onde começar. Afinal, os professores em nenhum momento foram presenciais (P 49).

- Para mim nenhum, pois se já é ruim aprender com o professor na sala de aula, imagina sem professor para tirar dúvidas (P 65).

- Nenhuma, pois o conteúdo é fraco e não temos nenhum tipo de explicação sobre os exercícios propostos (P 79).

Esses depoimentos evidenciam que alguns alunos não valorizam a EaD por se sentirem inseguros por não terem o acompanhamento dos professores nas dificuldades que encontram em sua aprendizagem. Isso se deve, entre outros fatores, à maneira como o curso está estruturado não possibilitando momentos de encontro entre $\mathrm{o}$ docente e os educandos, ou pela postura de alguns professores que ainda não estão em consonância com os preceitos da modalidade a distância, que defende o contato constante entre professor e o aluno por meio de encontros presenciais, tutorias, aulas ao vivo, chats, fóruns, e-mails entre outros.

As tecnologias de informação e comunicação já estão sendo incorporadas nas escolas brasileiras em todos os níveis, tendo 
apresentado um resultado favorável em alguns contextos. Porém:

- Na maioria das instituições, no entanto, elas são impostas como estratégia comercial e política, sem reflexão e sem a adequada reestruturação administrativa e sem a devida preparação do quadro de profissionais que ali atuam (KENSKI, 2006, p. 70).

Este é um aspecto que merece atenção, pois a formação de professores para atuar na $\mathrm{EaD}$ ainda hoje, carece de uma política que proporcione reflexões e desenvolva habilidades e competências frente a esta nova perspectiva educativa, uma vez que:

- A atuação de qualidade do professor brasileiro 'em um mundo em rede' vai depender de toda uma reorganização estrutural do sistema educacional, de valorização profissional da carreira docente e da melhoria significativa de sua formação, adaptando-o às novas exigências sociais e the oferecendo condições de permanentes aperfeiçoa mento e atualizaçãa (KENSKI, 2006, p.88).

Encontraram-se, também, quatro estudantes que dizem não gostar da $\mathrm{EaD}$, por afirmar preferir cursos presenciais:
- Ainda prefiro o curso real da sala de aula. Não gostei do curso a distância (p 20).

- Infelizmente nenhuma. Houve mais preocupações e perda de tempo ao invés de ganhos. Nada. Não deu para aprender muita coisa. Não me adaptei no ensino à distância (P 22)

- Pelo que vejo, no momento muito pouco. Prefiro as aulas presenciais (P 46).

Tais afirmativas revelam a falta de sintonia do estudante com a $\mathrm{EaD}$, o que ocorre por várias circunstâncias, mas merece destaque considerar que "No Brasil valorizam-se os contatos face a face; é uma cultura fortemente relacional. O trabalho solitário pode ser, então, uma limitação" (VERGARA, 2007).

A questão cultural e a formação que antecede a formação inicial universitária foram abordadas por um participante da pesquisa, que afirma:

- Eu acredito que o brasileiro ainda não está preparado para um curso a distância. Principalmente para os que estão saindo do ensino médio, pois eles não vem preparados para estudar em casa e nem tem disciplina para isso (P 34). 
Também é relevante destacar, conforme defende Vergara (2007), que no país ainda há grande desconfiança com a qualidade dos cursos a distância e ainda existe forte tradição da modalidade presencial, que, de certa maneira, reproduz as vivências e experiências educacionais da história escolar nacional desde o ensino fundamental, o que dá uma sensação de segurança e certo afastamento do desconhecido que a $\mathrm{EaD}$ apresenta.

\section{Considerações Finais}

O estudo possibilitou verificar o como a EaD está sendo avaliada pelos alunos participantes da pesquisa no que se refere ao aprendizado que esta modalidade de ensino proporciona ao educando.

Constatou-se que hoje a EaD é valorizada por boa parte dos alunos por possibilitar o acesso ao ensino superior por motivos diversos: a distância da moradia de instituições de ensino superior; questões relacionadas a dificuldades financeiras e/ou familiares, entre outros. Se, por um lado há a aceitação da EaD por motivos pessoais, notou-se que, por outro, boa parte dos participantes elogiam esta modalidade de ensino mas não se posicionam quanto ao processo de ensino-aprendizagem e à qualidade do curso oferecido.
Espera-se que os resultados desta pesquisa auxiliem as Instituições de Ensino, fornecendo subsídios para suas decisões quanto à estruturação, gestão e utilização de TICs para os cursos, tanto dos professores, dos cursos presenciais quanto os a distância, na elaboração de diferentes formas apresentação das aulas.

Nesse sentido, é importante dar continuidade à pesquisa, aprofundando os estudos teórico-empíricos sobre a percepção, o comportamento, o processo de ensinoaprendizagem e aquisição de competências e habilidades de forma interdisciplinar.

A presente pesquisa apresenta algumas limitações, a saber: (a) trata-se de uma investigação empírica, conduzida com alunos dos cursos presenciais e a distancia de uma instituição de ensino superior, sediada na Grande São Paulo, feita em abril de 2009, portanto, não se refere esta pesquisa a qualquer outro período de tempo, outra região geográfica ou objeto; (b) os pesquisados foram convidados a responder questionários específicos, presumindo-se que as respostas obtidas foram dadas efetivamente pelos respondentes a quem os questionários foram endereçados eletronicamente e expressam a opinião dos respondentes.

Dessa forma, apenas este conjunto de respostas foi levado em conta; (c) os dados coletados foram analisados pelas técnicas estatísticas descritas, consideradas adequadas à 
tipologia ordinal dos dados, pelo que os resultados das análises não levam em conta outras possíveis observações decorrentes do uso de outros instrumentos analíticos.

A pesquisa também é limitada pelos seguintes aspectos: (a) trata-se de uma pesquisa não probabilística e, por este fato, não é possível extrapolar os resultados para outros alunos ou outras instituições de ensino superiores (IES); (b) os resultados obtidos referem-se apenas ao conjunto de respondentes pesquisados considerando-se que as respostas aos questionários exprimem, de fato, o pensamento dos respondentes.

Referências Bibliográficas

ANTUNES, A. Aceita Um Conselho?: Como Organizar o Colegiado Escolar. São Paulo: Cortez, 2002.

ARANHA, M. L. DE A. História da educação e da pedagogia: geral e Brasil. São Paulo: Moderna, 2006.

ATHIYAMAN, A. Linking student satisfaction and service quality perceptions: the case of university education. European Journal of Marketing, v. 31, n. 7, p. 528-540, 1997.
CARSON, D. Qualitative marketing research. London; Thousand Oaks, Calif.: Sage Publications Ltd, 2001.

CASTELLS, M. A sociedade em rede. São Paulo: Paz e Terra, 2007.

CURWIN, J.; SLATER, R. Quantitative methods for business decisions. London: South-Western Cengage Learning, 2008.

GADOTTI, M. Pedagogia da terra. São Paulo: Editora Fundação Peirópolis, 2000.

HILSDORF, M. L. S. História da educação brasileira: leituras. São Paulo: Thomson, 2003.

HORA, D. M.; GONÇALVES, R. R.; COSTA, W. DA. A construção de uma proposta para o Estágio Supervisionado na modalidade a distância DOI: 10.5585/EccoS.v10i1.943. EccoS Revista Científica, v. 10, n. 1, p. 125-142, 2008.

KENSKI, V. M. Tecnologias e ensino presencial e a distância. Campinas: Papirus, 2006.

LARUCCIA, M. M. Da Organização Virtual à Organização Atual. Pensamento \& Realidade, v. 8, n. 1, p. 91-118, 2004a.

LARUCCIA, M. M. Notas sobre linguagem, comunicação e educação. Pensamento \& Realidade, v. 15, n. 1, p. 84-106, 2004b. 
LARUCCIA, M. M.; ALMEIDA, R. DE; RUIZ, T. T. O Desenvolvimento das Habilidades e Competências Profissionais de um Grupo de Estudantes de Administração. InterSciencePlace, v. 3, n. 11, p. 142-165, 2010.

LARUCCIA, M. M.; MELO, E. M. DE. A Percepção da Linguagem nas Relações ProfessorAluno. Pensamento \& Realidade, v. 24, n. 2, 2009.

LIMA, M. C. Monografia: A Engenharia da Produção Acadêmica. São Paulo: Saraiva, 2004.

LÜDKE, M.; ANDRÉ, M. E. D. A. DE. Pesquisa em Educação: Abordagens Qualitativas. São Paulo: EPU, 2008.

MANACORDA, M. A. História da educação: da antiguidade aos nossos dias. [s.l.] Cortez, 2002.

MASETTO, M. T. O Professor na Hora da Verdade: A prática docente no ensino superior. São Paulo: Avercamp, 2010.

MCDANIEL, C.; GATS, R. Pesquisa de Marketing. São Paulo: Pioneira, 2003.

MOORE, M. G. et al. Educacao a distancia uma visao integrada. Sao Paulo: Cengage Learning, 2007.

MORAN, J. M. Educação Inovadora na Sociedade da Informação. Disponível em: <http://www.serprofessoruniversitario.pro.br/le r.php? modulo $=10 \&$ texto $=560>$. Acesso em: 23 nov. 2010.

REIS, M. L. Relações entre a prática da educação a distância e a estrutura organizacional das universidades: processos de inovação e a tradição DOI: 10.5585/EccoS.v11i1.695. EccoS Revista Científica, v. 11, n. 1, p. 265-280, 2009.

ROMANOWSKI, J. P. Avaliação da aprendizagem na educação a distância: análise da prática, para início de conversa DOI: 10.5585/EccoS.v10i2.1360. EccoS - Revista Científica, v. 10, n. 2, p. 283-306, 2008.

SEGENREICH, S. C. D. Desafios da educação à distância ao sistema de educação superior: novas reflexões sobre o papel da avaliação. Educar em Revista, n. 28, p. 161 - 177, 2006.

SOUZA, A. S. Pesquisa qualitativa em administração. Revista de Administração Contemporânea, v. 10, n. 3, 2006.

TORI, R. Educação sem distância: as tecnologias interativas na redução de distâncias em ensino e aprendizagem. São Paulo: Senac, 2010.

VERGARA, S. C. Estreitando relacionamentos na educação a distância. Cadernos EBAPE.BR, v. 5, n. spe, p. 1-8, 2007. 
VERGARA, S. C. Content analysis as a qualitative data analysis technique in the field of administration: potentials and challenges. Revista de Administração Contemporânea, 2011.

VIEIRA, R. L. B.; FREITAS, K. S. DE. O SINAES na universidade pública estadual: análise do processo de construção da avaliação interna na Universidade do Estado da Bahia (UNEB). Ensaio: Avaliação e Políticas Públicas em Educação, v. 18, p. 443-464, set. 2010.

WERTHEIN, J. A sociedade da informação e seus desafios. Ciência da Informação, v. 29, n. 2, p. 71-77, 2000. 